\title{
Growth Patterns and Inequality in the Presence of Costly Technology Adoption
}

\author{
Radhika Lahiri* and Shyama Ratnasiri†
}

\begin{abstract}
The stylized facts that motivate this article include the diversity in growth patterns that are observed across countries during the process of economic development and the divergence over time in income distributions both within and across countries. We construct a dynamic general equilibrium model in which technology adoption is costly and agents are heterogeneous in their initial holdings of resources. We interpret the adoption cost as the resources expended in acquiring skills associated with new technologies. Endogenous growth occurs in our model largely as a result of human capital deepening. The analytical results of the model characterize three growth outcomes associated with the technology adoption process depending on productivity differences between the technologies. These outcomes are labeled 'poverty trap,' 'dual economy,' and 'balanced growth.' The model is then capable of explaining the observed diversity in growth patterns in addition to the divergence of incomes over time and across countries.
\end{abstract}

JEL Classification: O1, O11, 03

\section{Introduction}

There is substantial empirical evidence to indicate a 'twin peakedness' emerging in the world income distribution starting with the work of Quah $(1996,1997)$. There have been many studies explaining this type of characteristic in the world economy (see Durlauf and Quah [1996] and Islam [2003] and references therein). While bimodality in the world income distribution may not have been accepted as a stylized fact, there is some consensus about nonconvergence of incomes across countries. Bourguignon and Morrison (2002) suggest that while inequality in world income distributions has stabilized since the middle of the 20th century, there had been continuous divergence for at least a century prior to that time. Typically, the empirical evidence on economic growth supports Baumol's (1986) idea of "convergence clubs" emerging across and within countries.

This non-convergence has motivated various directions in theoretical research. A common explanation for persistence in inequality is based on the acquisition of human capital in some

* School of Economics and Finance, Queensland University of Technology, Brisbane, Australia; E-mail r.lahiri@qut.edu.au.

$\dagger$ Department of Accounting, Finance, and Economics, Griffith Business School, Griffith University, Gold Coast Campus, Australia; E-mail s.ratnasiri@griffith.edu.au; corresponding author.

We thank Greg Huffman; Kam Ki Tang; Tim Robinson; Paul Frijters; participants of the Econometric Society Australasia Meeting in 2007; participants at the 63rd International Atlantic Economics Conference, Madrid (2007); and participants at the 37th Australian Conference of Economics, Gold Coast, Australia (2008), for useful discussions and comments on an earlier version of this article. We also thank the editor and an anonymous referee for their constructive comments and criticisms. Any remaining errors are our responsibility.

Received October 2010; accepted August 2011. 
form. The articles by Chakraborty and Das (2005), Glomm and Ravikumar (1992), Glomm and Palumbo (1993), Ray and Streufert (1993), and Galor and Mayer-Foulkes (2002) offer a few examples of this type of literature. Another strand of literature focuses on delays in technology adoption as a source of international income divergence. Among many others, prominent examples in this line of research include those of Hansen and Prescott (2002), Parente and Prescott (1994, 2004), Greenwood and Jovanovic (1990), Ngai, (2004), Greenwood and Yorukoglu (1997), and Mokyr (1990, 1993).

Furthermore, Pritchett (1997) observes that the growth patterns of countries that fall into the "developing economies" category exhibit a great deal of diversity. For example, the economic growth of some of these countries converges rapidly on the leaders, while others stagnate or even experience reversals and declines in their growth processes. Pritchett cites the experience of Mozambique ( $-2.2 \%$ per annum) and Guyana $(-0.7 \%$ per annum) as examples from a group of 16 developing economies that experienced negative growth rates in the 1960 1992 period. To our knowledge there is no theoretical literature that provides a unified explanation for this diversity in growth patterns. That is, no single model in the literature captures the idea of reversals, stagnation, and economic growth in a unified framework.

The model developed in this article has elements in common with the various branches of literature cited above. First, we explore the idea that delays in technology adoption cause persistence in inequalities. Secondly, the delay in technology adoption in our model occurs as a result of the lack of resources expended in acquiring skill-intensive human capital. Basically, the adoption cost in our model refers to two types of costs associated with acquiring new technologies. One type of cost is the 'learning by doing' cost associated with technical change. The second type of cost is manifested in the learning of new skills required to operate state-of-the-art technology.

Put differently, our model expresses the idea suggested in Tinbergen (1975) that inequality and growth are determined by the "race between technological development and education." In our model we do not explicitly model endogenous technological development as in, for example, the models of Howitt (1999) and Acemoglu and Robinson (2002). However, endogenous growth in our model occurs through human capital deepening somewhat similar in spirit to the type of capital deepening that is associated with the Romer (1987) model with 'AK' technology. This human capital deepening, though, is inextricably linked to the presence of technical change and the learning/skill-acquisition costs associated with it.

The structure of our model is similar to that of Khan and Ravikumar (2002) (henceforth $\mathrm{KR}$ ), which grafts the AK structure in a heterogeneous agent model of infinitely lived dynasties and includes a fixed cost of adopting new technologies. However, as a result of our adoption of an overlapping generations construct some key differences emerge in the context of our model. First, in our model the adoption decision takes place in every generation of households, while in the KR model the technology adoption decision is a one-time irreversible decision, which is perhaps natural in the context of infinitely lived agents. Our innovation introduces the idea that there are many technological developments over time and that agents need to incur adoption costs associated with them many times. Secondly, in the KR model capital is interpreted as a composite of human and physical capital, with an emphasis on the human capital element. In our model we have an even greater emphasis on the human capital element of this composite good. This brings into play a different interpretation for the adoption costs in our model; again, it is the human capital acquisition associated with new technologies that we emphasize.

An important motivation for introducing an adoption decision that takes place every period relates to the idea that this feature may be associated with the diversity of growth 
patterns observed in the data. In particular, extant models of technology adoption are unable to explain the reversals in the process of economic growth that are experienced by some countries. As will become clear later, this feature of the model produces reversals in the output growth of dynasties that are a part of the lower end of the initial distribution of income and wealth in the economy. For example, a poor household undertaking the switching decision may leave a smaller amount in bequests than would otherwise have been the case. Consequently, the next generation may not have enough resources to be able to adopt the better technology, leading to a reversal of the growth process.

Indirect evidence in support of this idea stems from discussions of trends in education, inequality, and technology adoption observed in late 19th century to the 1990s in the United States. See, for example, Goldin and Katz (2008), who point out that cohorts born in the early part of this period (from 1870 to 1950) experienced an increase of 0.8 years of schooling with every new generation. This increase coincided with falling levels of inequality and rapid technological improvement, a trend that continued until the 1970s. However the post-1970s period is characterized by stagnation in educational attainment and an increase in inequality. According to Goldin and Katz, the 'productivity slowdown' of the 1990s was a culmination of these trends.

We find that the above-mentioned feature of the model - that the technology adoption decision takes place for every generation of agents - is indeed able to characterize growth outcomes of a very diverse nature. Specifically, depending on initial productivity differences there are three possibilities. In one situation the model produces a poverty trap. In the second situation a dual-economy type of scenario results, while in the third situation there is balanced growth for all agents in the economy. To our knowledge, no single model that is able to characterize all of these scenarios has been developed in the related literature.

The numerical experiments conducted using the model unearth some interesting and empirically testable implications for the transitional process of economies, most of which have been explored only to a limited degree by previous studies. The model finds that assumptions about the initial distribution of wealth and capital can have very different implications for the date at which all households in the economy adopt the better technology. Specifically, the higher the initial level of inequality, the later is the date of complete adoption of the better technology. Inequality can therefore increase and remain persistent for very long periods of time, consequently delaying the process of structural transformation that is associated with development.

Measuring 'technology adoption' and 'adoption costs' at the aggregate level is a challenging task. We therefore design a simple empirical test of this idea, based on an indirect proxy for the extent of technology adoption. In our model the concept of technology adoption is closely linked to the idea of human capital accumulation or deepening. This 'deepening,' to some extent, could be measured by a proxy using the Barro and Lee (2010) panel data set on 'average years of schooling.' Using various measures of this variable at the secondary and tertiary levels we investigate the link between 'initial inequality,' as measured by the Gini coefficient of income levels for various countries, and our proxy for human capital deepening. The estimate of "initial inequality" here is based on the measure of Gini coefficients dated approximately around the date of the country's transition to "modern economic growth" in the sense characterized by Kuznets (1955) (see also Hansen and Prescott [2002]). However, since it is not always possible to get the relevant estimate of inequality for all of the countries in the sample, we use the nearest possible consistently measured estimate of initial inequality in those 
cases. Our results support the hypothesis indicated by the model; the link between human capital deepening and initial level of inequality is indeed negative, indicating the policy implication that redistributive expenditures will have a positive impact on the economy. However, we include such measures as control variables in our regressions and find that the link is positive and significant in some, but not all, of the specifications considered.

The following section describes the economic environment used to address the issues described above. In particular, section 2 presents the general version of the model with the key theoretical results. Section 3 details the results of the numerical experiments conducted with a view to providing an intuition for the theoretical outcomes. Some of the empirically testable implications of the results unearthed in previous sections are examined using a panel data set in section 4, which also outlines some directions for future empirical research. Section 5 concludes this article. The Appendix presents proofs of various propositions presented in section 2.

\section{The Economic Environment}

The model presented here consists of two-period lived overlapping generations of agents. There are $N$ agents in the economy, and they are heterogeneous in their holdings of wealth and capital. An agent born in period $t$ inherits a certain amount of capital and wealth. The initial distributions of capital and wealth are described by $F($.$) , and G($.$) , respectively. Time is$ discrete, with $t=0,1,2, \ldots$. The preferences of $i$ th agent born in period $t$ are described as follows:

$$
U\left(c_{i t}, c_{i t+1}, x_{i t+1}, s_{i t+1}\right)=\ln \left(c_{i t}\right)+\beta \ln \left(c_{i t+1}\right)+\beta \theta_{1} \ln \left(x_{i t+1}\right)+\beta \theta_{2} \ln \left(s_{i t+1}\right)
$$

Here, $c_{i t}$ and $c_{i t+1}$ denote the agents' consumption in the first and second period of life, respectively. Each agent is born with a unit of unskilled labor endowment that may be used to earn a subsistence wage $\bar{w}$. They also receive resources in the form of bequests from their parents. Part of this bequest is given by $x_{i t+1}$, which represents the resources left to the next generation after the death of the parents. Parents also provide children with a share, $\alpha$, of their second-period income. This second component of bequests received by the children of the agents born in period $t$ is represented by the variable $s_{i t+1}$. The parameter $\beta$ is the subjective discount factor in this model, and $\theta_{1}$ and $\theta_{2}$ are parameters representing the extent of imperfect intergenerational altruism in the model.

In each period $t$, individuals have to decide to adopt one of two technologies, which will then be used to produce output. These two technologies are referred to as Technology $A_{t}$ and Technology $B_{t}$. For ease of reference we will often refer to these as Technology $A$ and Technology $B$ in our discussions, except in situations in which it is important to specify the time period involved.

Technology $A$ is associated with lower productivity but does not involve any adoption costs. Technology $B$ is associated with higher productivity and involves an adoption cost $(\delta)$, incurred in the agent's youth. The economy produces output $(Y)$ using capital $(K)$, and the production relationships $F(K)$ assume simple " $A K$ " specifications. We emphasize that the variable $K$ in this model represents a composite good consisting of both human and physical capital but with a dominant human capital component. Here, the total factor productivities associated with the two technologies are denoted by parameters $A_{t}$ and $B_{t}$, where $B_{t}>A_{t}$. 
Note also that the model here has a structure similar to that of the KR model, but the key difference is that here there is a two-period overlapping-generations structure. Khan and Ravikumar consider an infinite horizon model with non-overlapping generations and a one-time adoption cost, after which the Technology $A$ is never used. In the model here, each generation faces a technology adoption problem, even if the previous generation belonging to the same cohort had adopted Technology $B$. However, the fact that every generation faces a technology adoption problem changes the interpretation of our model in subtle ways that require further elaboration. From an intuitive point of view it seems implausible that every generation has to 'reinvent' a technology that already existed in the previous periods. However, since we have interpreted our technologies as highly human capital intensive, we look at the concept of 'adoption' in relation to acquiring educational skills for operating advanced technologies.

Secondly, we introduce an exogenous growth component to reflect the idea that technological changes are taking place over time and that these changes are manifested in the productivity growth of the existing technologies. How this technological change takes place is not explicitly modeled in this framework, but the presence of such change implicitly reflects the notion that new technologies are being invented, and the skills needed to operate them have to be learned in every period. The adoption costs associated with the Technology $B$ are the relatively higher educational and 'learning by doing' costs.

Specifically, the rate of total factor productivity grows at a constant rate, $g$, which represents technological change over time. We assume that this rate of growth is the same for both types of technologies. This also means that the relative productivities of Technology $B$ and Technology $A$ do not change over time. This means that

$$
\frac{B_{t}}{A_{t}}=\frac{B_{t-1}}{A_{t-1}}=\ldots=\frac{B_{0}}{A_{0}}=\eta, \quad \text { where } \eta>1 .
$$

In relation to the point made above, there are two possible ways to interpret this technological change. The best way to present our ideas is in the tabular form, and to that end we present Table 1 .

In what follows, however, we do not impose any restrictions on $\eta$ and $g$. In the case of our theoretical results we focus on the special case of $g=0$, which abstracts from exogenous growth and focuses only on the endogenous growth component of our model. In our numerical experiments we simulate the model with $g>0$ but present results that involve variables detrended of this exogenous growth component. The reason for introducing the parameter $g$, then, is primarily that in its absence, the model could be interpreted in a way that is unpalatable from an intuitive point of view. As mentioned before, without $g$ we are in an environment in which every new generation has to 'reinvent the wheel,' so to speak. However, exogenous growth does matter in this framework; our numerical simulations, which are presented in section 3, indicate that the timing of technology adoption is hastened as a result of the additional growth component. Qualitatively speaking, however, there are no changes in the results due to the incorporation of exogenous growth.

The agents born in period $t$ use their wage-income and resource endowment for consumption and capital accumulation in the first period. In the second period they use returns on their capital holdings to finance consumption and bequests. Households adopting Technology $A$ face the following budget constraints:

$$
c_{i t}^{a}+K_{i t+1}^{a}=\bar{w}+W_{i t}
$$


Table 1. Interpretation of Technological Change

\begin{tabular}{|c|c|c|c|}
\hline & Case I: $\eta=(1+g)$ & Case II: $\eta>(1+g)$ & Case III: $\eta<(1+g)$ \\
\hline \multicolumn{4}{|l|}{ Interpretation I } \\
\hline $\begin{array}{l}\text { The two technologies } \\
\text { in existence are being } \\
\text { 'upgraded' or replaced } \\
\text { by new technologies that } \\
\text { have productivity }(1+g) \\
\text { times their previous } \\
\text { versions. } \\
\text { The two technologies in } \\
\text { their previous forms are } \\
\text { no longer available or in } \\
\text { existence in the current } \\
\text { period. }\end{array}$ & $\begin{array}{l}\text { Here, in any given } \\
\text { period the } \\
\text { productivity of } \\
\text { technology A } \\
\text { becomes equal to the } \\
\text { productivity of } \\
\text { technology B from } \\
\text { the previous period. }\end{array}$ & $\begin{array}{l}\text { Here, in any given } \\
\text { period the } \\
\text { productivity of } \\
\text { technology A is still } \\
\text { e less than the } \\
\text { productivity of } \\
\text { technology B in the } \\
\text { previous period. }\end{array}$ & $\begin{array}{l}\text { Here, in any given } \\
\text { period the } \\
\text { productivity of } \\
\text { technology } \mathrm{A} \text { is } \\
\text { more than the } \\
\text { productivity of } \\
\text { technology B in the } \\
\text { previous period. }\end{array}$ \\
\hline \multicolumn{4}{|l|}{ Interpretation II } \\
\hline $\begin{array}{l}\text { A 'technological switch' } \\
\text { has taken place in which } \\
\text { the technology B of the } \\
\text { previous period has } \\
\text { become the technology } \\
\text { A of this period. } \\
\text { The new technology } \\
\text { of this period has been } \\
\text { labeled B, while the } \\
\text { old technology of the } \\
\text { previous period has } \\
\text { been re-labeled as A. } \\
\text { The previous period's } \\
\text { technology A does not } \\
\text { exist anymore. }\end{array}$ & $\begin{array}{l}\text { Here, the fact that } \\
\text { the old technology } \\
\text { is operating in the } \\
\text { environment of this } \\
\text { period has led to } \\
\text { no change in its } \\
\text { productivity. } \\
\text { There have been no } \\
\text { additional gains } \\
\text { from learning by } \\
\text { doing. Likewise, the } \\
\text { current environment } \\
\text { has not changed to } \\
\text { the extent that it } \\
\text { makes the old } \\
\text { technology less } \\
\text { productive than it } \\
\text { was before. }\end{array}$ & $\begin{array}{l}\text { Today's technology } \\
\text { A is less productive } \\
\text { than it was in the } \\
\text { past because the } \\
\text { environment in } \\
\text { which it operates has } \\
\text { changed. To provide } \\
\text { an analogy, this is } \\
\text { similar to the case in } \\
\text { which old computer } \\
\text { hardware is no } \\
\text { longer compatible } \\
\text { with new software } \\
\text { that has been } \\
\text { invented in the } \\
\text { current period. }\end{array}$ & $\begin{array}{l}\text { In this case } \\
\text { technology A is } \\
\text { more productive } \\
\text { than its previous } \\
\text { version, perhaps } \\
\text { because the } \\
\text { learning by doing } \\
\text { gains have not been } \\
\text { exhausted. As this } \\
\text { technology has } \\
\text { been in operation } \\
\text { for a longer time, } \\
\text { people have learned } \\
\text { to operate it more } \\
\text { efficiently. }\end{array}$ \\
\hline
\end{tabular}

and

$$
c_{i t+1}^{a}=(1-\alpha) A_{t} K_{i t+1}^{a}-x_{i t+1}^{a} .
$$

Here, $c_{i t}^{a}, c_{i t+1}^{a}$, and $K_{i t+1}^{a}$ refer to first-period consumption, second-period consumption, and second-period capital holding of $i$ th individual adopting Technology $A$. The variable $W_{i t}$ represents the resource endowment of the $i$ th agent in period $t$. In this model the resource endowment of an agent depends on the technology that was adopted by the agent's parents. This means that $W_{i t}=W_{i t}^{a}=x_{i t}^{a}+s_{i t}^{a}$ if the agent's parent adopted Technology $A$, and $W_{i t}=$ $W_{i t}^{b}=x_{i t}^{b}+s_{i t}^{b}$ if the agent's parent adopted Technology $B$. Here, the bequests that arise from agents' second-period income $\left(s_{i t}^{a}\right)=\alpha A_{t} K_{t}$ if the agents adopted Technology $A$, and $\left(s_{i t}^{b}\right)=$ $\alpha B_{t} K_{t}$ if the agents adopted Technology $B$. As is evident from the budget constraints, these resources may be converted by the young for the purpose of consumption as well as capital accumulation. Note that the "AK" structure of production functions assumed here is typically known to generate non-convergence in incomes across countries. See, for example, the work of Mankiw, Romer, and Weil (1992) and references therein. 
Households adopting Technology $B$, on the other hand, face the following constraints:

$$
c_{i t}^{b}+K_{i t+1}^{b}=\bar{w}+W_{i t}-\delta
$$

and

$$
c_{i t+1}^{b}=(1-\alpha) B_{t} K_{i t+1}^{b}-x_{i t+1}^{b} .
$$

In these equations all of the variables are interpreted as before, with superscript ' $b$ ' denoting the fact that the agents are adopting Technology $B$. As mentioned above, $\delta$ is the cost of adopting Technology $B$.

Note also that the model here has a structure similar to that of the KR model, but the key difference is that here there is a two-period overlapping-generations structure. Khan and Ravikumar consider an infinite horizon model with non-overlapping generations and a onetime adoption cost, after which Technology $A$ is never used. In the model here, each generation faces a technology adoption problem, even if the previous generation belonging to the same cohort had adopted Technology B. It appears that the overlapping-generations structure imposed here has very different implications for the outcomes of the model.

For agents adopting Technology $A$, the optimal plans for consumption, bequests, and capital accumulation are described by the following equations. In the equations below we have use the fact that $A_{t}=(1+g)^{t} A_{0}$ and $B_{t}=(1+g)^{t} B_{0}$, where $A_{0}$ and $B_{0}$ represent the period-zero productivity levels of the respective technologies. Furthermore, since we are analyzing the special case in which $g=0, A_{t}=A_{0}$ and $B_{t}=B_{0} \forall t$,

$$
\begin{gathered}
c_{i t}^{a}=\frac{1}{(1+\phi)}\left[\bar{w}+W_{i t}\right], \\
c_{i t+1}^{a}=A_{0} \frac{(1-\alpha)}{\left(1+\theta_{1}\right)} \frac{\phi}{(1+\phi)}\left[\bar{w}+W_{i t}\right], \\
x_{i t+1}^{a}=\theta_{1} A_{0} \frac{(1-\alpha)}{\left(1+\theta_{1}\right)} \frac{\phi}{(1+\phi)}\left[\bar{w}+W_{i t}\right], \\
K_{i t+1}^{a}=\frac{\phi}{(1+\phi)}\left[\bar{w}+W_{i t}\right] .
\end{gathered}
$$

Likewise, the agents who adopt $B$ will have

$$
\begin{gathered}
c_{i t}^{b}=\frac{1}{(1+\phi)}\left[\bar{w}+W_{i t}-\delta\right], \\
c_{i t+1}^{b}=B_{0} \frac{(1-\alpha)}{\left(1+\theta_{1}\right)} \frac{\phi}{(1+\phi)}\left[\bar{w}+W_{i t}-\delta\right], \\
x_{i t+1}^{b}=\theta_{1} B_{0} \frac{(1-\alpha)}{\left(1+\theta_{1}\right)} \frac{\phi}{(1+\phi)}\left[\bar{w}+W_{i t}-\delta\right], \\
K_{i t+1}^{b}=\frac{\phi}{(1+\phi)}\left[\bar{w}+W_{i t}-\delta\right],
\end{gathered}
$$

where, $\phi=\beta\left(1+\theta_{1}+\theta_{2}\right)$. 
The $i$ th agent will adopt technology $B$ if and only if

$$
U^{B}\left(K_{i t}, x_{i t}, s_{i t}\right) \geq U^{A}\left(K_{i t}, x_{i t}, s_{i t}\right),
$$

where $U^{A}$ and $U^{B}$ represent the indirect utility functions for agents adopting the $A$ and $B$ technologies, respectively. It is then easy to show that this implies the following:

Proposition 1. Let

$$
W^{*}=\frac{\delta}{1-\left(\frac{1}{\eta}\right)^{\sigma}}-\bar{w} ; \quad \text { where } \quad \sigma=\frac{\phi}{1+\phi} \quad \text { and } \quad \eta=\frac{B_{0}}{A_{0}} .
$$

A household will adopt technology $B$ if and only if $W_{i t} \geq W^{*}$.

The above proposition defines a threshold level of resources required for a household to find it worthwhile to adopt the more productive Technology B. (See Appendix 1 for a proof of this proposition.)

In earlier work, Khan and Ravikumar (2002) derive a unique threshold level of capital above which households will adopt the more productive technology and show that this threshold level is independent of preference parameters. In contrast to their analysis, the threshold level of resources in this model depends on technology parameters, preference parameters, and adoption costs associated with Technology $B$.

Note that, as in Khan and Ravikumar (2002), the inclusion of borrowing to finance technology adoption does not affect the outcomes of our model. Basically, since the form of technology adoption in our model is a human capital intensive activity, access to loans might not help the agent to adopt Technology $B$. However, if they are able to access consumption loans, it might make it easier for them to do so. The household that wants to borrow, in the context of our model, can only do so from agents who are willing to lend, and these agents are the ones who have adopted Technology $B$. This means that they will have to pay back such loans at an interest rate, $r$, equal to at least $B-1$, the net return on the $B$ technology. Nevertheless, it may not be worthwhile to borrow. This is because the return on investment for a household that borrows to adopt the new technology exceeds $A-1$ but is less than $B-1$. Consequently, such a household will not be willing to borrow at the interest rate $B-1{ }^{1}$

The dynamics of this model are described by the following system of first-order difference equations.

$$
\left.\begin{array}{l}
K_{i t+1}^{a}=\frac{\phi}{(1+\phi)}\left[\bar{w}+W_{i t}\right] \\
x_{i t+1}^{a}=\theta_{1} A_{0} \frac{(1-\alpha)}{\left(1+\theta_{1}\right)} \frac{\phi}{1+\phi}\left[\bar{w}+W_{i t}\right]
\end{array}\right\} \quad \text { for } \quad W_{i t}<W^{*}
$$

and

$$
\left.\begin{array}{l}
K_{i t+1}^{b}=\frac{\phi}{(1+\phi)}\left[\bar{w}+W_{i t}-\delta\right] \\
x_{i t+1}^{b}=\theta_{1} B_{0} \frac{(1-\alpha)}{\left(1+\theta_{1}\right)} \frac{\phi}{(1+\phi)}\left[\bar{w}+W_{i t}-\delta\right]
\end{array}\right\} \quad \text { for } \quad W_{i t}>W^{*}
$$

\footnotetext{
${ }^{1}$ Of course, one may consider a small open economy variant of our model in which it is possible to borrow at a 'world interest rate' that is lower than $B-1$. But that would be a more complicated extension, which we leave as a future direction of research.
} 
where

$$
W^{*}=\frac{\delta}{1-\left(\frac{1}{\eta}\right)^{\sigma}}-\bar{w},
$$

with $\sigma$ and $\eta$ defined as in Proposition 1. Note that if adoption costs are household-specific stochastic shocks the threshold level of resources varies over time and across households.

The following discussion derives some analytical predictions of this model. Here a steadystate level of resources $\left(W^{s}\right)$ is defined using the definition of resources stated above. ${ }^{2}$ If it exists, the steady-state level of resources that corresponds to the two technologies in this economy is given as

$$
W^{s}=\left\{\begin{array}{ll}
\frac{(\bar{w}-\delta)}{\left(1 / \gamma_{b}\right)-1} ; & \text { if } W_{i t}>W^{*} \\
\frac{\bar{w}}{\left(1 / \gamma_{a}\right)-1} ; & \text { if } W_{i t}<W^{*}
\end{array} .\right.
$$

Here

$$
\gamma_{a}=\left[\frac{A_{0} \phi}{(1+\phi)}\left(\frac{\theta_{1}(1-\alpha)}{\left(1+\theta_{1}\right)}+\alpha\right)\right] \quad \text { and } \quad \gamma_{b}=\left[\frac{B_{0} \phi}{(1+\phi)}\left(\frac{\theta_{1}(1-\alpha)}{\left(1+\theta_{1}\right)}+\alpha\right)\right]
$$

In the above equation, the steady-state level of resources corresponding to Technology $A$ is determined by productivity parameters, preference parameters, and subsistence wage rate $\bar{w}$. In addition to these three variables, the steady-state level of resources corresponding to Technology $B$ also depends on adoption costs associated with Technology $B$. Note that the parameter $\gamma$ embodies productivity levels of technologies and the agents' preferences in this economy.

Having defined the 'steady states,' we are in a position to discuss the dynamics of the system. The dynamics are represented by the evolution of bequests over time, and using the fact that total bequests $W_{i t+1}=x_{i t+1}+s_{i t+1}$, they can be represented by

$$
W_{i t+1}^{a}=\gamma_{a}\left[\bar{w}+W_{i t}\right] \quad \text { if } \quad W_{i t}<W^{*}
$$

and

$$
W_{i t+1}^{b}=\gamma_{b}\left[\bar{w}+W_{i t}-\delta\right] \quad \text { if } \quad W_{i t}<W^{*} .
$$

It is then clear that the dynamics will depend on the 'slopes' $\gamma_{a}$ and $\gamma_{b}$ and how they compare with the $45^{\circ}$ line, which has a slope of 1 . Figure 1 illustrates relationship between parameter $\gamma$ and the productivities of technologies represented as $P$ where $P=A$ or $B$. The symbol $P^{*}$ refers to the productivity level at which $\gamma_{a}$ or $\gamma_{b}=1$ for the technology in question.

Depending on the productivity difference between the two technologies, the model has diverse implications for the process of technology adoption and economic growth. There are three different cases, namely (i) $A_{0}<B_{0}<P^{*}$, (ii) $A_{0}<P^{*}<B_{0}$, and (iii) $P^{*}<A_{0}<B_{0}$, which are labeled 'poverty trap,' 'dual economy,' and 'balanced growth,' respectively.

(i) Poverty trap: If $A_{0}<B_{0}<P^{*}$, this economy converges to a unique steady state under Technology $A$. Here, both slope coefficients $\gamma_{a}$ and $\gamma_{b}$ are less than 1 , and the productivities of both technologies are relatively 'low' in that sense. This can be further explained by looking at the equilibrium dynamics illustrated in Figure 2a. In this figure, the vertical axis refers to $W_{i t+1}$, while the horizontal axis refers to $W_{i t}$. The

\footnotetext{
${ }^{2}$ See Appendix 2 for the proof.
} 


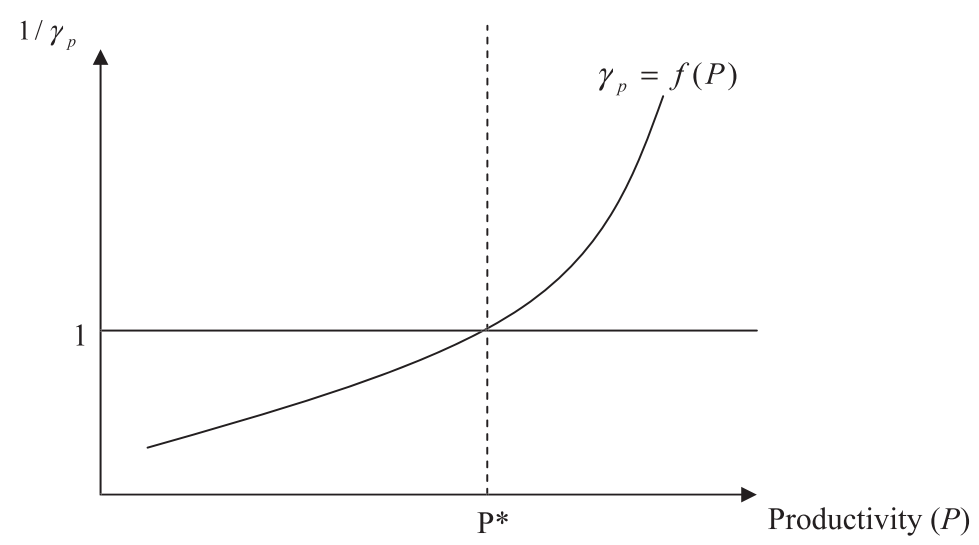

Figure 1. The Values of Productivity Parameters that Determine Various Properties of the Model (Here $p=a, b$, and $\mathrm{P}=\mathrm{A}, \mathrm{B})$

equilibrium dynamics for Technology $A$ are given by $W_{i t+1}^{a}=\gamma_{a}\left(W_{i t}+\bar{w}\right)$, while the same dynamics for Technology $B$ are given by $W_{i t+1}^{b}=\gamma_{b}\left(W_{i t}+\bar{w}-\delta_{i t}\right)$. Therefore, the resource accumulation under Technology $A$ is given by the line $A-A^{\prime}$, while resource accumulation under Technology $B$ is given by the line $B-B^{\prime}$. As shown in the figure, there is a unique steady state in this economy that corresponds to Technology $A$, and it is denoted by $W_{A}^{s}$. As we show in the numerical experiments of the next section, inequality within this economy increases in the transition process to the steady state. Once all agents have adopted Technology $A$, inequality starts to decrease, eventually converging to zero.

(ii) Dual economy: If $A_{0}<P^{*}<B_{0}$, the economy uses both technologies. Here the slope coefficient associated with Technology $A$ is less than 1 , and that associated with Technology $B$ is $>1$. As illustrated in Figure $2 b$, the households with resources above $W_{B}^{s}$ (i.e., the unstable steady-state level of resources corresponding to Technology $B$ ) adopt Technology $B$ and experience continuous growth. The households who hold resources below $W_{B}^{s}$ reach a stable steady state under Technology $A$. The inequality within this economy increases in the transition process and is persistent. The growth rates of the two different groups of households do not converge and remain distinct. This situation can be considered representative of a dual economy in which one group of agents falls into stagnation while others experience growth. The models in the literature that produce such features are numerous. See, for example, the work of Bourguignon (1990) and references therein.

(iii) Balanced growth: If $P^{*}<A_{0}<B_{0}$, this economy is characterized by balanced growth. As illustrated in Figure $2 \mathrm{c}$ all households in the economy eventually adopt Technology $B$. The inequality within this economy increases over time and is persistent. As all households in this economy adopt Technology $B$, the rate of growth of the economy corresponds to the rate of growth of Technology $B$.

\section{Results of Numerical Experiments and Discussion}

In this section we discuss the intuition underlying the theoretical results reported above by means of a set of numerical experiments. The parameter values used for experiments are as 
a

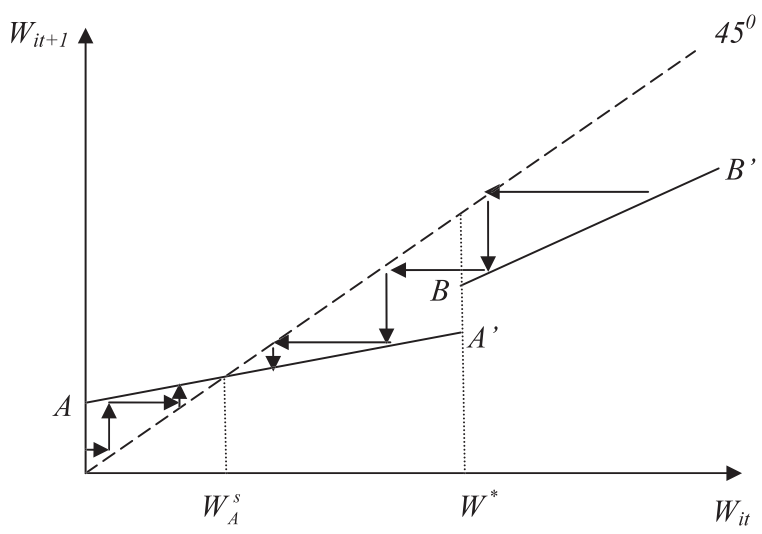

b
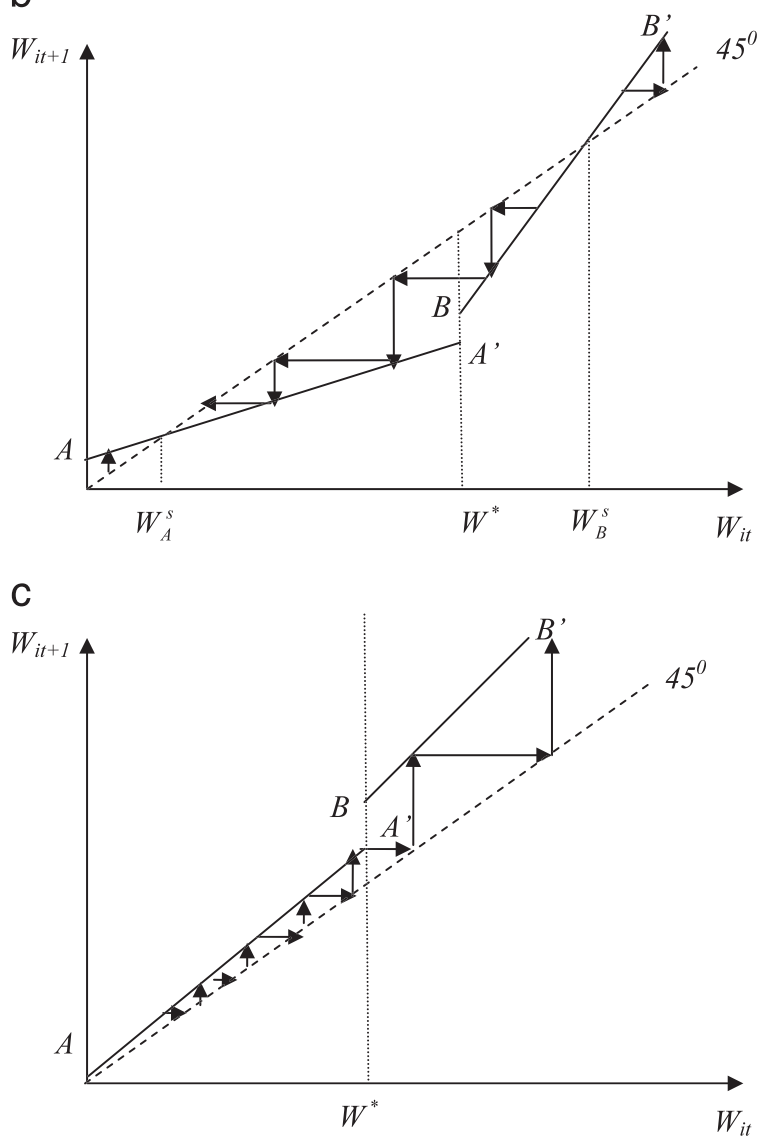

Figure 2. (a) Poverty trap. (b) Dual economy.

follows: $\beta=0.95, \theta_{1}=\theta_{2}=0.95, \alpha=0.05$, and $\bar{w}=1$. The initial distributions of capital and wealth are assumed to be lognormal, with a mean of 3.6 and a variance of 1.2.

First, this section provides a numerical analysis of the three cases (i.e., poverty trap, dual economy, and balanced growth) mentioned above. The productivity parameter values 
(a)

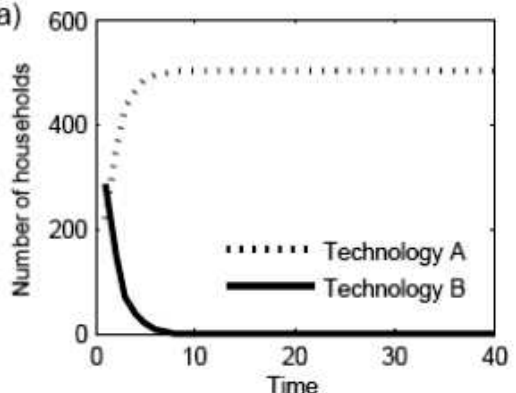

(c)

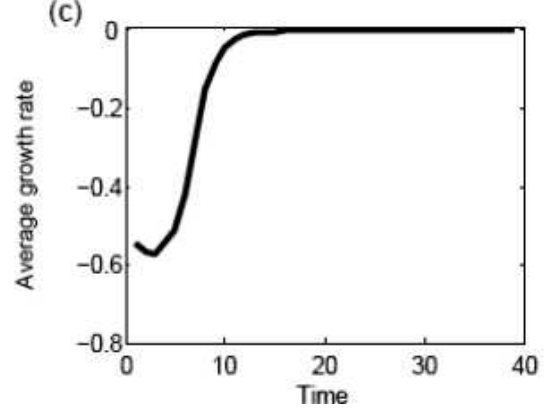

(b)

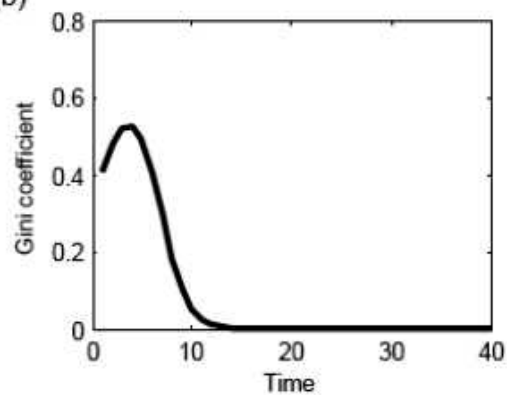

(d)

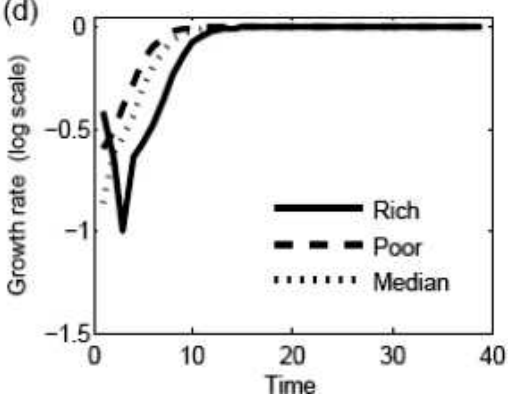

Figure 3a. Technology Adoption, Inequality, and Economic Growth in the Case of Poverty Trap

associated with these cases are presented in summary form in Table 1 . Recall that $P^{*}$ is the value of the productivity level at which $\gamma$ in Equation 18 equals 1.

Figure $3 \mathrm{a}$ shows the implications for technology adoption and economic growth in the case in which $A<B<P^{*}$, which was labeled "poverty trap." Panel "a" of this figure shows the number of households adopting Technology $A$ or $B$ in different time periods, while panel "b" shows the evolution of inequality in this economy over time. The average rate of growth in this economy is given in panel "c," while the growth rates experienced by various cohorts of households in the income distribution are presented in panel "d." In this case all agents in the economy eventually adopt Technology $A$, as illustrated in Figure 2a.

Furthermore, as mentioned in the previous section, the inequality within this economy initially increases in the transition process, before the eventual decline in inequality. Basically, the initial distribution of income and wealth implies that there are two sets of households. One set adopts Technology $A$ while the other set adopts Technology $B$. Over time set $A$ increases as those households at the lower end of set $B$ do not leave sufficient resources for their offspring because of the high cost of adopting Technology $B$. The resources of each subsequent generation decline over time to the point that only adopting Technology $A$ is feasible. Once all agents have adopted Technology $A$ inequality starts to decrease, and it eventually converges to zero. The rate of growth of all agents in this economy eventually increases from a negative growth rate in the transition process and converges to zero. This has an obvious implication for the sectoral growth rates of households in Technology $A$ and $B$, respectively. Since all households are adopting Technology $A$ eventually the economy stagnates.

Figure $3 \mathrm{~b}$ looks at similar implications for the case that is labeled "dual economy." Here, the economy uses both technologies in the steady state, as illustrated previously in Figure $2 \mathrm{~b}$. It is apparent that the steady state of this economy involves two distinct sectors growing at 
(a)

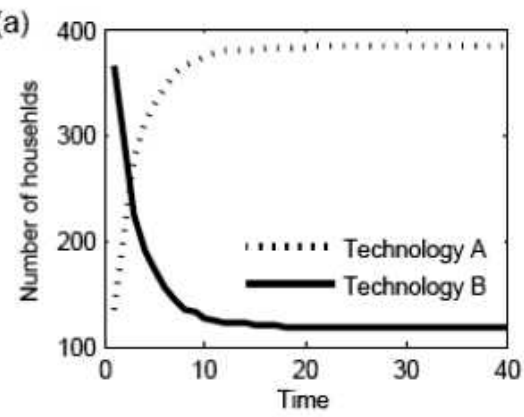

(c)

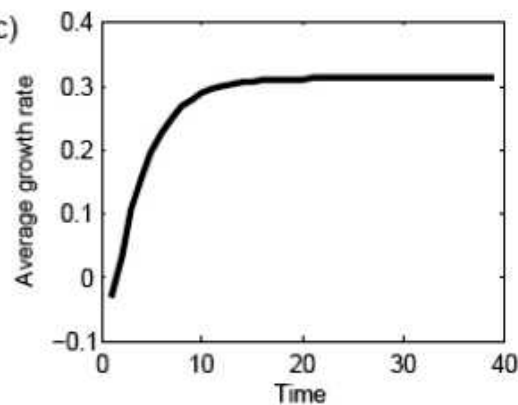

(b)

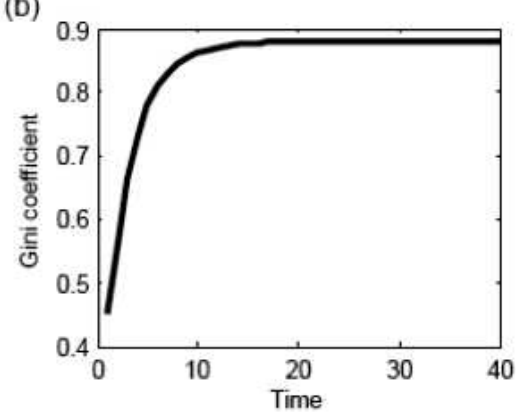

(d)

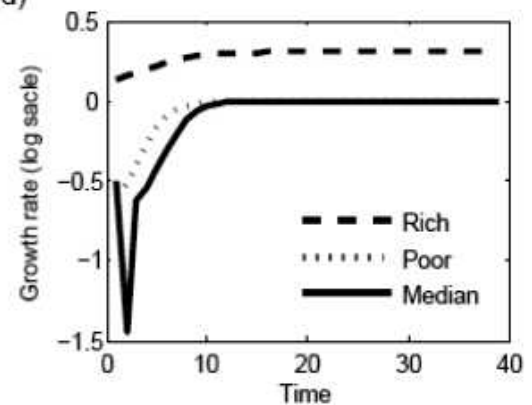

Figure 3b. Technology Adoption, Inequality, and Economic Growth in the Case of Dual Economy

different rates. An obvious implication of this characteristic is that inequality in this economy will increase in the transition process and remain persistent.

Figure $3 c$ explores the implications for the case that is labeled "balanced growth." In this case, both technologies have productivities that are large enough to allow households to grow

(a)

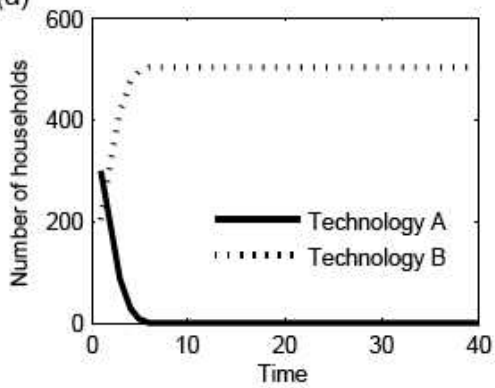

(c)

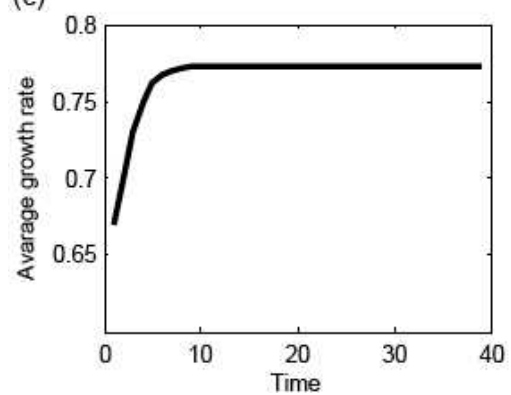

(b)

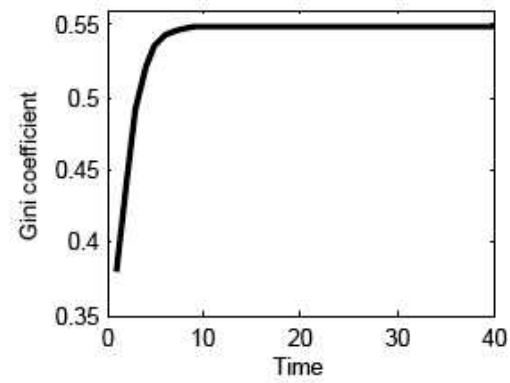

(d)

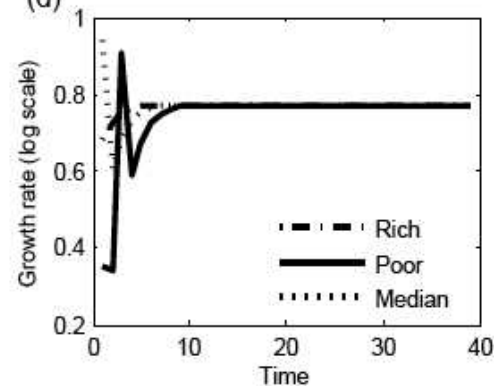

Figure 3c. Technology Adoption, Inequality, and Economic Growth in the Case of Balanced Growth 
at a relatively higher rate. Therefore, all agents in the economy eventually adopt Technology $B$ (see, again, the section that analyzes Figure $2 \mathrm{c}$ and the discussion associated with it). The inequality in this economy is increasing in the transition process and remains persistent. Intuitively, it is apparent that households that switch to the more productive technology sooner accumulate more resources than do households that delay the switch to the productive technology. As all agents adopt Technology $B$ the growth rates of the output of agents in this economy eventually converge.

As mentioned previously, our model is capable of producing diverse growth patterns for agents in the different cohorts of income distribution. Here we look at the growth patterns experienced by various cohorts of households in income distribution in detail. All three cases reported above look at the rate of growth of output for the median, richest $20 \%$, and poorest $20 \%$ of the households of the income distribution. In the three figures above (viz., Figure 3a, b, and c) it appears that the growth pattern for different cohorts of households is very diverse.

For example, in the case that is labeled "poverty trap," the growth rates of all households start with a negative value (see panel "d" of Figure 3a). Over time, however, the growth rates of the poorer and the median households monotonically increase, while rich agents experience a reversal. Intuitively, as all agents at the richer end of the income distribution jump from Technology $B$ to Technology $A$, their growth rate is characterized by a reversal at the beginning. Eventually growth rates of all households converge, but the economy experiences stagnation.

From panel "d" of Figure 3b, which corresponds to the case of the dual economy, it is clear that growth patterns of both the richer and the poorer agents are smooth and monotonic, while median agents experience reversals. This can be explained as follows. Initially there are two sets of households in the income distribution of this economy. The poorer end consists of one set that adopts Technology $A$, while the richer end consists of the other set that adopts Technology $B$. Again, as agents in the lower end of set $B$ jump from Technology $B$ to Technology $A$, their growth rate is characterized by a reversal at the beginning. Then, over time, the growth rates of these households converge to the growth rate of poorer households. As a result, in the steady state the economy is characterized by two distinct rates of growth that correspond to the two technologies.

The "balanced growth" case shows a monotonically increasing growth rate experienced by richer agents, while the poorer and the median agents have a variable pattern (see panel "d" of Figure 3c). In the case of the poorer and the median households, however, a very high savings rate is required prior to reaching the stage at which the household is able to make the switching decision. When the households make the switching decision they incur a heavy cost of adoption, so the amount invested in the new technology is relatively low. Therefore, these agents experience a temporary reversal in the growth rate of output. In the steady state, however, the rates of growth of the different groups of households converge, and the economy is characterized by a permanent and stable growth rate.

The model's ability to generate a diverse set of patterns for growth rates of households at different positions in the income distribution is worthy of comment here. A critique of contemporary growth models has often been related to their inability to explain the patterns of reversals in the growth process that have been experienced by several countries even after they embarked on modern economic growth (Pritchett 2000). If agents in our model are interpreted as countries that occupy various positions in the world income distribution, the model here can be regarded as an explanatory step in the direction of such phenomena. We observe these types 
of growth performance in different countries/regions around the world. For example, it can be suggested that the poverty trap type of phenomenon may be observed in countries such as Zaire, Uganda, Rwanda, and Nepal, among many others, because they are well behind the world technology frontier, they experience extended periods of stagnation, and their per capita incomes are strictly less than the international poverty line (i.e., \$2 a day) (Maddison 2009).

Moreover, our results indicate that growth rates in an economy with more altruistic households converge to a higher level in the steady state, when compared with growth rates in an economy with more non-altruistic households. The rationale for this phenomenon is that if the parents are more altruistic, their children are more likely to adopt the productive technology sooner, as they receive more resources in terms of bequests.

\section{Empirics}

In this section we attempt to examine empirically whether initial inequality matters for the timing of technology adoption. Recognizing that in our model, the timing/extent of technology adoption correlates with the extent of human capital deepening that has taken place, an appropriate measure of the 'extent of technology adoption' in the aggregate can be constructed by looking directly at a measure of human capital accumulation. A possible candidate to proxy human capital deepening could be based on the levels of secondary or tertiary schooling in any given country. Such a measure is easily available, as, for example in the data set on 'average years of schooling' compiled in Barro and Lee (2010). We convert this variable to 'human capital' using the approach followed by Hall and Jones (1999) and Caselli (2005). Specifically, we convert the 'average years of schooling' into a measure of human capital $(h)$ using the formula $h_{i t}=\exp \left(v s_{i t}\right)$, where $s$ is the average years of schooling and $v$ is the Mincerian rate of return to an extra year of schooling. ${ }^{3}$ In our empirical tests, we set $v_{s}=0.101$, which reflects the average returns to schooling around the world. An estimate of a $10.1 \%$ return for a year of schooling is based on the empirical analysis in Banerjee and Duflo (2005). ${ }^{4}$

We estimate the link between initial inequality and the 'extent of technology adoption' by regressing our measure of human capital on the initial level of inequality, controlling for other variables, such as educational expenditures of the government, the per capita GDP, and government transfers as a percentage of GDP, and our proxy for human capital deepening by using a panel data set for 85 countries for time periods extending from 1995 to 2005. Since the Barro and Lee data set only provides five-year averages of their 'years of schooling' variable, we have only two observations corresponding to time periods, for which we take averages of all the control variable appearing in the regressions.

The initial level of inequality is measured using the Gini coefficient $(G N)$, which is the main independent variable in our analysis, in addition to variables measuring the expenditure on education $(E D U)$, redistributive government expenditures $(T R)$, and per capita income $(I)$.

\footnotetext{
${ }^{3}$ In the growth-accounting literature, Mincerian rates of return are commonly used to estimate a country's human capital. For details see Caselli (2002, 2005) and Hall and Jones (1999). In addition, see Caselli (2003) for a survey of development accounting methods.

${ }^{4}$ Specifically, they run a cross-country regression of Mincerian rates on average years of schooling. See also Psacharopoulos and Patrinos (2002), on which the Banerjee and Duflo results are based, and Caselli (2005).
} 
Table 2. Parameter Values

\begin{tabular}{lcc}
\hline Parameter $\left(P^{*}=2.9\right)$ & $A_{0}$ & $B_{0}$ \\
\hline Poverty trap $\left(A<B<P^{*}\right)$ & 1 & 2 \\
Dual economy $\left(A<P^{*}<B\right)$ & 2 & 3 \\
Balanced growth $\left(P^{*}<A<B\right)$ & 3 & 5 \\
\hline
\end{tabular}

As mentioned before, the estimate of "initial inequality" here is based on the measure of Gini coefficients dated approximately around the date of the country's transition to "modern economic growth" in the sense characterized by Kuznets (1955; see also Hansen and Prescott [2002]). Estimates of "initial inequality" are taken from version 2.b of the World Income Inequality Database (WIID), which is an updated version of the Deininger and Squire (1996) database. However, since it is not always possible to obtain the relevant estimate of inequality for all of the countries in the sample, the nearest possible consistently measured estimate of initial inequality of the countries is used in this analysis. For some of the developing economies in the sample, the closest available estimate is dated approximately around 1964. However, countries for which a reasonable measure of "initial inequality" is not available were excluded from the sample.

We estimate a model of the form

$$
H_{i t}=\alpha+\beta_{1} G N_{i}+\beta_{2} I_{i t}+\beta_{3} E D U_{i t}+\beta_{4} T R_{i t}+\varepsilon_{i t},
$$

where $H_{i t}$ is the our proxy measure of human capital deepening of country $i$ at time $t$ and $G N_{i}$, $I_{i t}, E D U_{i t}$, and $T R_{i t}$ are the explanatory variables discussed above for $i$ th country at time $t{ }^{5}$ The error component is $\varepsilon_{i}$, and it has usual properties $\left(\varepsilon_{i} \sim N(0,1)\right)^{6}$

Based on our theoretical analysis, we expect the sign of the coefficient of 'initial inequality' to be negative; that is, higher initial inequality delays technology adoption and is consequently associated with a smaller extent of human capital deepening. Secondly, we expect redistributive expenditures, either in the form of spending on education or transfers of other kinds to matter in a positive way. In our regressions we measure the corresponding variable for educational expenditure $E D U_{i t}$ by using the variable titled 'Public spending on education as \% of GDP' from World Development Indicators (WDI) 2010 database. Likewise, our proxy for $T R_{i t}$ is also taken from the same database and consists of transfers and subsidies as a percent of government revenue. A priori, then, the coefficients $\beta_{3}$ and $\beta_{4}$ are expected to be positive and significant. Of course, the coefficient of $I_{i t}$, measured by log of per capita GDP, also taken from WDI, should be positive and significant; the higher the income level, the higher the extent of human capital accumulation.

We estimate the above model using the pooled ordinary least squares (OLS) and random effects specifications. ${ }^{7}$ Our results are presented in Table 3. The table includes robustness checks in the form of a different proxy for the dependent variable. Specifically, we look at

\footnotetext{
${ }^{5}$ Note that our measure of initial inequality does not have a $t$ subscript because 'initial' inequality does not vary over time. Therefore, in our panel the variable for inequality has variation across countries but not over time. All other variables have variation in both the time and country dimensions.

${ }^{6}$ Note that in the random effects estimator, we segregate the unobserved country-specific characteristics from this error term.

${ }^{7}$ Note that our independent variable 'initial inequality' does not vary over time. This creates a problem with estimating the fixed effects panel data model, as controlling for country-specific effects leads to co-linearity of the country-specific dummies with this variable.
} 


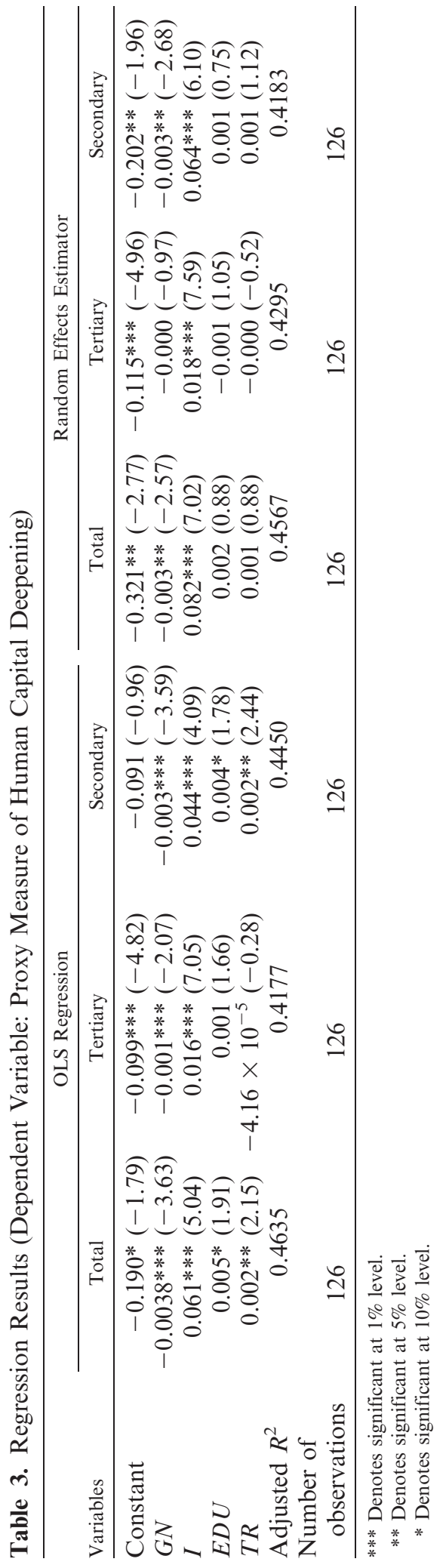


'average years of schooling' at the secondary and tertiary levels and also a composite variable, labeled 'Total,' including both secondary and tertiary levels of education.

As is evident from the regressions, the coefficient of our 'initial inequality' variable is negative and significant for most of the regressions, implying that higher levels of initial inequality lead to a lower level of human capital deepening and, consequently, technology adoption. The only exception occurs in the random effects specification when the dependent variable is measured by average 'tertiary' years of schooling, which is somewhat surprising given that the tertiary level is representative of a higher degree of skill. Note, however, that in all cases the coefficients are very small in magnitude. In the pooled OLS case, for example, when the dependent variable is measured by the average 'tertiary' years of schooling, capital deepening will increase only by $0.001 \%$ for a $1 \%$ decrease in initial inequality. These coefficients are consistent with the estimates of other studies; for example, a study that explores the link between contemporary income inequality and educational attainment by Gregorio and Lee (2002) also reports negative but fairly small coefficients. In the random effects specification, too, the coefficients are small. In this case the interpretation that applies to the coefficient is slightly different: $0.003 \%$ is the average decrease in human capital deepening when inequality changes over time and across countries by $1 \%$.

However, the results are not conclusive with regard to the impact of redistributive expenditures as measured by our variables $E D U_{i t}$ and $T R_{i t}$. While the signs of the coefficients are mostly correct, they are significant only in the pooled OLS case, and that, too, is significant at the $10 \%$ level. Furthermore, the magnitudes of these coefficients are not very large. For example, when the dependent variable is measured by the average 'total' years of schooling, the magnitude of the coefficient $E D U_{i t}$ is 0.005 . The fact that expenditure on education has a positive but rather small effect on educational attainment has also been reported by Heinesen and Graverse (2005). The coefficient of per capita GDP, though, is positive at highly significant levels in all of the regressions.

Overall, then, we can conclude that there is indirect support for the key implication of our model, namely the negative link between initial inequality and the extent of technology adoption. As far as the implications of redistributive expenditures are concerned, we haven't addressed this issue directly within the context of our model. This would entail modeling the role of government by introducing taxes and expenditures in a realistic way. The conclusions of such a model could then inform empirical research by enabling the choice of a better specification for the empirical model relative to the one considered in this section. We believe that this would be an interesting direction of future research.

\section{Concluding Remarks}

Empirical evidence indicates that there has been a divergence over time in income distributions across countries and within countries. Furthermore, there is a great deal of diversity in the growth experiences of these countries. This article studies a simple heterogeneous agent, dynamic general equilibrium model capable of explaining these facts. In this model technology adoption is costly and growth takes place through human capital deepening. Depending on initial productivity differences our model is able to characterize three different growth outcomes that are labeled "poverty trap," "dual economy," and "balanced 
growth." Further findings indicate that in the presence of barriers or costs associated with the adoption of more productive technologies, inequalities in wealth and income may increase over time, tending to delay the convergence in international income differences. In terms of the model, delays in technology adoption are related to the initial inequality in the resource distribution of the agents.

The results of the empirical study presented in this article appear to support the model's prediction that initial inequality has a negative impact on technology adoption, as represented by the extent of human capital deepening that has taken place in the economy. Some of our regressions also support the policy implication that redistributive expenditures can have a beneficial impact on the level of education and, consequently, human capital in a country, thereby bringing about a reduction in inequality over time.

\section{Appendix 1: Proof of Proposition 1}

Households adopt Technology $B$ if and only if (iff) the indirect utility of Technology $B$ is greater than the indirect utility of Technology $A$. This implies that households adopt Technology $B$

$$
\text { iff } U^{b}\left(c_{i t}^{b}, c_{i t+1}^{b}, x_{i t+1}^{b}, s_{i t+1}^{b}\right) \geq U^{a}\left(c_{i t}^{a}, c_{i t+1}^{a}, x_{i t+1}^{a}, s_{i t+1}^{a}\right) .
$$

Substituting for the functional forms we get

$$
\begin{aligned}
\ln \left(c_{i t}^{b}\right)+\beta \ln \left(c_{i t+1}^{b}\right)+\beta \theta_{1} \ln \left(x_{i t+1}^{b}\right)+\beta \theta_{2} \ln \left(s_{i t+1}^{b}\right) \geq \\
\ln \left(c_{i t}^{a}\right)+\beta \ln \left(c_{i t+1}^{a}\right)+\beta \theta_{1} \ln \left(x_{i t+1}^{a}\right)+\beta \theta_{2} \ln \left(s_{i t+1}^{a}\right) .
\end{aligned}
$$

Recall that, here, $\left(s_{i t+1}^{a}\right)=\alpha A_{0} K_{t+1}$ and $\left(s_{i t+1}^{a}\right)=\alpha B_{0} K_{t+1}$.

In addition, rewrite Equations 6-8 in terms of $\left(c_{i t}^{a}\right)$ and Equations 10-13 in terms of $\left(c_{i t}^{b}\right)$. Then substitute them into the above inequality. After simplifying,

$$
\begin{aligned}
\ln \left(c_{i t}^{b}\right)+ & \beta \ln \beta(1-\alpha) A_{0}\left(\frac{1+\theta_{1}+\theta_{2}}{1+\theta_{1}}\right) c_{i t}^{b}+\beta \theta_{1} \ln \theta_{1} \beta(1-\alpha) A_{0}\left(\frac{1+\theta_{1}+\theta_{2}}{1+\theta_{1}}\right) c_{i t}^{b} \\
& +\beta \theta_{2} \ln \alpha A_{t+1} \beta\left(1+\theta_{1}+\theta_{2}\right) c_{i t}^{b} \geq \ln \left(c_{i t}^{a}\right)+\beta \ln \beta(1-\alpha) A_{0}\left(\frac{1+\theta_{1}+\theta_{2}}{1+\theta_{1}}\right) c_{i t}^{a} \\
& +\beta \theta_{1} \ln \theta_{1} \beta(1-\alpha) A_{0}\left(\frac{1+\theta_{1}+\theta_{2}}{1+\theta_{1}}\right) c_{i t}^{a}+\beta \theta_{2} \ln \alpha A_{0} \beta\left(1+\theta_{1}+\theta_{2}\right) c_{i t}^{a} .
\end{aligned}
$$

This means that agents will adopt Technology $B$

$$
\begin{aligned}
& \text { iff } \ln \left(c_{i t}^{b}\right)^{1+\beta+\beta \theta_{1}+\beta \theta_{2}}-\ln \left(c_{i t}^{a}\right)^{1+\beta+\beta \theta_{1}+\beta \theta_{2}} \geq \ln \left(A_{0}\right)^{\beta+\beta \theta_{1}+\beta \theta_{2}}-\ln \left(B_{0}\right)^{\beta+\beta \theta_{1}+\beta \theta_{2}} \\
& \text { iff } \ln \left(\frac{c_{i t}^{b}}{c_{i t}^{a}}\right)^{1+\beta+\beta \theta_{1}+\beta \theta_{2}} \geq \ln \left(\frac{A_{0}}{B_{0}}\right)^{\beta+\beta \theta_{1}+\beta \theta_{2}} .
\end{aligned}
$$

Substituting for $c_{i t}^{a}, c_{i t}^{b}$ (in Eqns. 7 and 11 in the text), it is possible to define the threshold level of resources required for households to adopt more productive technology $\left(W^{*}\right)$, as follows.

$$
W^{*}=\frac{\delta}{1-\left(\frac{1}{\eta}\right)^{\sigma}}-\bar{w} ;
$$

where $\sigma$ and $\eta$ are defined previously.

\section{Appendix 2: Derivation of Equation 18}

As discussed in section 2 of our article, if $W_{i t}<W^{*}$, then agents adopt Technology $A$. From our definition of resources that are provided to the next generation, in this case, $W_{i t+1}=x_{i t+1}+s_{i t+1}$, where $s_{i t+1}=\alpha A_{0} K_{i t+1}$. (Recall that we are analyzing the case in which $g=0, A_{t}=A_{0} \forall t$ ).

This means $W_{i t+1}=x_{i t+1}+\alpha A_{0} K_{i t+1}$. 
Substituting Equations 9 and 10 from section 2 of our article into the above equation we get

$$
W_{i t+1}=\theta_{1} A_{0} \frac{(1-\alpha)}{\left(1+\theta_{1}\right)} \frac{\varphi}{(1+\varphi)}\left[\bar{w}+W_{i t}\right] \quad+\alpha A_{0}\left[\frac{\varphi}{(1+\varphi)}\left[\bar{w}+W_{i t}\right]\right] .
$$

To derive the steady-state level of resources, $W_{A}^{s}$, we note that in the steady state $W_{i t+1}=W_{i t}=W_{A}^{s}$, and we can write the above equation as

$$
W_{A}^{s}=\theta_{1} A_{0} \frac{(1-\alpha)}{\left(1+\theta_{1}\right)} \frac{\varphi}{(1+\varphi)}\left[\bar{w}+W_{A}^{s}\right] \quad+\alpha A_{0}\left[\frac{\varphi}{(1+\varphi)}\left[\bar{w}+W_{A}^{s}\right]\right] .
$$

After rearranging and simplifying, we get

$$
W_{A}^{s}=\frac{\bar{w}}{\left(1 / \gamma_{a}\right)-1} ; \quad \text { if } W_{i t}<W^{*}, \quad \text { where } \gamma_{a}=\left[\frac{A_{0} \varphi}{(1+\varphi)}\left(\frac{\theta_{1}(1-\alpha)}{\left(1+\theta_{1}\right)}+\alpha\right)\right] \text {. }
$$

In the case of Technology $B$ we can similarly derive

$W_{B}^{s}=\frac{(\bar{w}-\delta)}{\left(1 / \gamma_{b}\right)-1} ; \quad$ if $W_{i t}>W^{*}, \quad$ where $\gamma_{b}=\left[\frac{B_{0} \varphi}{(1+\varphi)}\left(\frac{\theta_{1}(1-\alpha)}{\left(1+\theta_{1}\right)}+\alpha\right)\right]$.

Combining the above we get Equation 18 of section 2.

\section{References}

Acemoglu, D., and J. A. Robinson. 2002. The political economy of the Kuznets Curve. Review of Development Economics 6:183-203.

Aghion, P., and P. Bolton. 1997. A theory of trickle down effect and development. Review of Economic Studies 64:151-72.

Banerjee, A., and D. Duflo. 2005. Growth theory through the lens of development economics. In Handbook of economic growth, volume 1A, edited by P. Aghion and S. Durlauf. Amsterdam: Elsevier, pp. 473-552.

Baumol, W. 1986. Productivity growth, convergence, and welfare: What the long-run data show? American Economic Review 76:1072-85.

Benabou, R. 1996. Inequality and growth. In NBER macroeconomic annual 1996, edited by B. S. Bernanke and J. J. Rotemberg. Cambridge, MA: MIT Press, pp. 11-74.

Bessen, J. 2002. Technology adoption costs and productivity growth: The transition to information technology. Review of Economic Dynamics 5:443-69.

Bourguignon, F. 1990. Growth and inequality in the dual model of development: The role of demand factors. Review of Economic Studies 57:215-28.

Bourguignon and Morrison. 2002. Inequality among world citizens 1820-1993. American Economic Review 92:727-45.

Caselli, F., and W. J. Coleman. 2001. Cross-country technology diffusion: The case of computers. American Economic Review 91:328-35.

Chakraborty, S., and M. Das. 2005. Mortality, human capital and persistent inequality. Journal of Economic Growth 10:159-92.

Deininger, K., and L. Squire. 1996. A new dataset measuring income inequality. The World Bank Economic Review 10:565-91.

Djankov, S., R. La Porta, F. Lopez-De-Silanes, and A. Shleifer. 2002. The regulation of entry. Quarterly Journal of Economics 65:1-37.

Durlauf, S., and D. T. Quah. 1996. The new empirics of economic growth. In Handbook of macroeconomics, 1st edition, volume 1, edited by J. B. Taylor and M. Woodford. Elsevier, pp. 235-308.

Forbes, K. J. 2000. A reassessment of the relationship between inequality and growth. American Economic Review 90:869-87.

Galor, O. 1996. Convergence? Inferences from theoretical models. Economic Journal 106:1056-69.

Galor and Mayer-Foulkes. 2004. Food for thought: Basic needs and persistent educational inequality. Mimeo, Brown University.

Galor, O., and J. Zeira. 1993. Income distribution and macroeconomics. Review of Economic Studies 60:35-52.

Glomm, G., and M. Palumbo. 1993. Optimal intertemporal consumption decisions under the threat of starvation. Journal of Development Economics 42:271-91.

Glomm, G., and B. Ravikumar. 1992. Public versus private investment in human capital: Endogenous growth and income inequality. Journal of Political Economy 100:818-34.

Greenwood, J., and B. Jovanovic. 1990. Financial development, growth and the distribution of income. Journal of Political Economy 98:1076-106. 
Greenwood, J., and M. Yorukoglu. 1997. 1974: Carnegie-Rochester Conference Series on Public Policy, 46:49-95.

Gregorio, J., and J. H. Lee. 2002. Education and income inequality: New evidence from cross country data. Review of Income and Wealth 48:395-415.

Hansen, G., and E. Prescott. 2002. Malthus to Solow. American Economic Review 92:1205-17.

Heinesen, E., and B. K. Graverse. 2005. The effect of school resources on educational attainment: Evidence from Denmark. Bulletin of Economic Research 57:109-43.

Hornstein, A., and P. Krusell. 1996. Can technology improvements cause productivity slowdown? In NBER macroeconomics annual, edited by B. Bernanke and J. Rotemberg. Cambridge, MA: MIT Press.

Jappelli, T., and L. Pistaferri. 2000. The dynamics of household wealth accumulation in Italy. Fiscal Studies 21:269-95.

Khan, A., and B. Ravikumar. 2002. Costly technology adoption and capital accumulation. Review of Economic Dynamics 5:489-502.

Kuznets, S. 1955. Economic growth and income inequality. American Economic Review 65:1-28.

Maddison, A. 2009. Historical statistics of the world economy: 1-2006AD. Available http://www.ggdc.net/maddison.

Mankiw, N. G., D. Romer, and D. N. Weil. 1992. A contribution to the empirics of economic growth. Quarterly Journal of Economics 107:407-37.

Mokyr, J. 1990. The lever of riches: Technological creativity and economic progress. New York: Oxford University.

Mokyr, J. 1993. The new economic history and the Industrial Revolution. In The British Industrial Revolution: An economic perspective, edited by J. Mokyr. Boulder, CO: Westview Press.

Nazrul, I. 2003. What have we learnt from the convergence debate? Journal of Economic Surveys 17:309-62.

Ngai, L. R. 2004. Barriers and the transition to modern growth. Journal of Monetary Economics 51:1353-83.

Parente, S., and E. Prescott. 1994. Barriers to technology adoption and development. Journal of Political Economy 102:298-301.

Parente, S., and E. Prescott. 2004. A unified theory of the evolution of international income levels. Federal Reserve Bank of Minneapolis, Research Department Staff Report 333.

Piketty, T., and E. Saez. 2003. Income inequality in the United States. Quarterly Journal of Economics 118:1-39.

Pritchett, L. 1997. Divergence, big time. Journal of Economic Perspectives 11:3-17.

Pritchett, L. 2000. Understanding patterns of economic growth: Searching for hills among plateaus, mountains, and plains. The World Bank Economic Review 14:221-50.

Psacharopoulos, G., and H. A. Patrinos. 2004. Returns to investment in education: A further update. Education Economics 12:111-38.

Quah, D. T. 1996. Twin peaks: Growth and convergence in models of distribution dynamics. Economic Journal 106:1045-55.

Quah, D. T. 1997. Empirics for economic growth and distribution: Polarization, stratification and convergence clubs. Journal of Economic Growth 2:27-59.

Ray, Debraj, and Peter A. Streufert. 1993. Dynamic equilibria with unemployment due to undernourishment. Economic Theory 3:61-85.

Sala-i-Martin, X. 2006. The world distribution of income: Falling poverty and ... convergence, period. Quarterly Journal of Economics 121:351-97.

Schluter, C. 1998. Income dynamics in Germany, the USA and the UK: Evidence from panel data. Centre for Analysis of Social Exclusion CASE Papers.

Tomes, N. 1981. The family, inheritance and intergenerational transmission of inequality. The Journal of Political Economy 89:928-57.

United Nations Development Program. 2006. Human development report 2006. Beyond scarcity: Power, poverty and the water crisis.

United Nations University World Institute for Development Economics Research (WIDER). 2008. Available http:// www.wider.unu.edu/research/Database/en_GB/database/. 